\title{
Don PanUncio y El Tigre
}

\section{Don Panuncio and The Tiger}

\author{
Leonardo Fernández-Badillo
}

\section{Universidad Autónoma del Estado de Hidalgo}

\section{fernandezbadillo80@gmail.com}

orcid.org/0000-0002-0855-138X

Recibido: 8 de enero de 2021.

Aceptado: 10 de abril de 2021 .

\section{Resumen}

Una de las estrategias de manejo para mitigar el conflicto humano-serpiente ha sido el uso de la translocación a larga distancia. El presente documento relata una historia relacionada con este conflicto y con el trabajo de translocación que realizan los brigadistas comunitarios de las Áreas Naturales Protegidas de Hidalgo, dedicados al rescate y conservación de serpientes.

Palabras clave: Translocación, conflicto, rescate, conservación.

\begin{abstract}
One of the management strategies used to mitigate the human-snake conflict has been long distance translocation. The present document tells a history related to this conflict and to the translocation actions carried out by community brigades dedicated to the rescue and conservation of snakes in the Natural Protected Areas of Hidalgo .
\end{abstract}

Key words: Translocation, conflict, rescue, conservation.

\section{Introducción}

La translocación a larga distancia es una estrategia de manejo que ha sido empleada para mitigar el conflicto humano-serpiente, de este modo los ejemplares nocivos son trasladados fuera de su ámbito hogareño, a zonas en las cuales no puedan entrar en conflicto con los humanos (Nowak et al., 2002; Sullivan et al., 2014). Actualmente en la Reserva de la Biosfera Barranca de Metztitlán (RBBM), al igual que en otras dos áreas naturales protegidas del estado de Hidalgo (Parque Nacional El Chico y Parque Nacional Los Mármoles), se cuenta con brigadas comunitarias de rescate y conservación de serpientes, las cuales buscan protegerlas y evitar los accidentes ofídicos, es decir, las mordeduras de serpientes venenosas. Para ello, las brigadas fueron capacitadas por miembros del equipo de trabajo del Herpetario X-Plora Reptilia, con recursos del Programa de Conservación para el Desarrollo Sostenible (PROCODES). La capacitación se centró en temas sobre el manejo seguro de serpientes, primeros auxilios en caso de mordedura, rescate y translocación de serpientes, entre otros. 
Particularmente en la RBBM, el mayor conflicto ocurre con la serpiente venenosa Crotalus atrox, la especie de serpiente de cascabel más grande de México (Heimes, 2016) y protagonista del evento. Se distribuye ampliamente y se puede encontrar en zonas de cultivo y áreas urbanas, lo que representa un riesgo para los pobladores.

El presente cuento está dedicado a todos los pobladores miembros de las brigadas de estas áreas naturales protegidas, quienes han decidido dedicar parte de su tiempo a la protección y conservación de las serpientes.

\section{Cuento}

Otro día más en la vida de Don Panuncio, una vida como la de cualquier otro, con cosas buenas y cosas malas, algunas muy malas, por cierto, como aquella época de escasez de comida cuando tuvo que andar mucho por el desierto para encontrarla o cuando casi muere a causa de una herida que le marcó la cara para siempre. Pero, a pesar de todo eso, Don Panuncio fue creciendo y pudo convertirse en uno de los más respetados de la región, y quizás de los más sabios de toda la Barranca de Metztitlán. Don Panuncio era sin duda imponente, con cara de pocos amigos, pero con una actitud pacífica y calmada. Los jóvenes de su especie lo admiraban, a veces lo veían pasar cerca de la Peña del Cuervo o lo encontraban tomando el sol a la sombra del gran garambullo y susurraban, "mira, mira, ahí está Don Panu", "Hay que pasar rápido, no se vaya a enojar", y no es que él fuera enojón, pero su tamaño y esa cicatriz en la cabeza, le daban un aspecto temerario.

Los días pasaban como siempre, pero algo en la mente de Panuncio siempre daba vueltas, una idea que iba y venía como la luna y la primavera, y aunque en ocasiones se desvanecía, siempre regresaba. Era la loca idea de probar suerte en el pueblo, ahí el agua era abundante por la cercanía del río, y la comida ni se diga, era muy fácil conseguirla y había muchas construcciones extrañas en donde poder refugiarse. Pero Don Panuncio sabía que el pueblo era peligroso, muchos lo habían intentado y nunca regresaron, otros habían corrido con suerte por algún tiempo, pero tampoco volvieron. Y es que el pueblo nunca sería lugar para una serpiente y mucho menos para una como Don Panuncio, cuyo veneno y cascabel al final de la cola aterraban a las personas. Poco importaba que a Don Panuncio no le interesaran las personas y que en su naturaleza no existiera el odio, ni las ganas de hacerle daño a alguien, los pobladores siempre lo verían como un animal peligroso y tratarían de matarlo si lo descubrían merodeando entre sus tierras, mismas que por antigüedad y derecho pertenecían a Don Panuncio, pues las serpientes aparecieron mucho tiempo antes que los humanos.

Con todo y estos peligros, Don Panuncio decidió ir al pueblo, era quizás la única aventura que le faltaba, y con su metro setenta de longitud y su experiencia pensó que podría tener suerte. Afinó su cascabel, mudó de piel para ir de gala y reluciente, no quería que lo vieran todo shengo. Tomó el camino viejo a Texcado y tardó varios días en llegar, pero finalmente lo logró, exhausto, con sed y con mucha hambre,
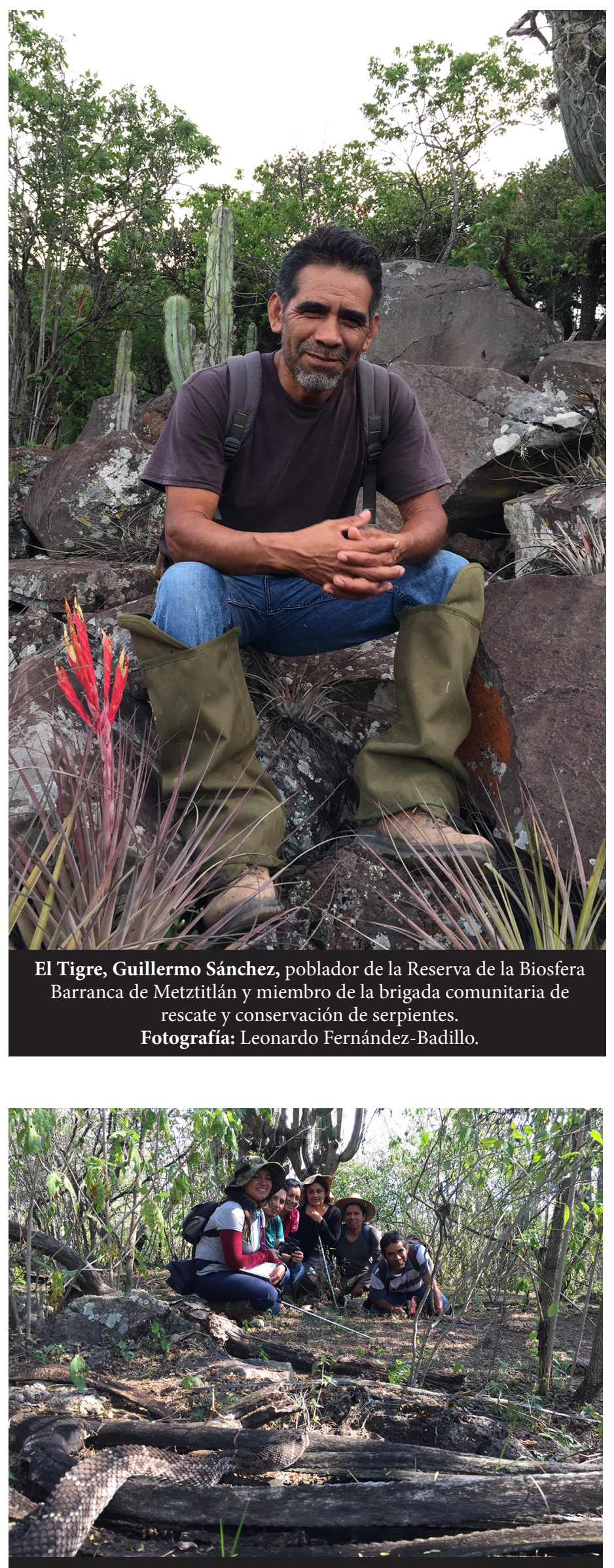

Don Panuncio en su refugio al ser descubierto por El Tigre, Guillermo Sánchez. Fotografía: Leonardo Fernández-Badillo. 


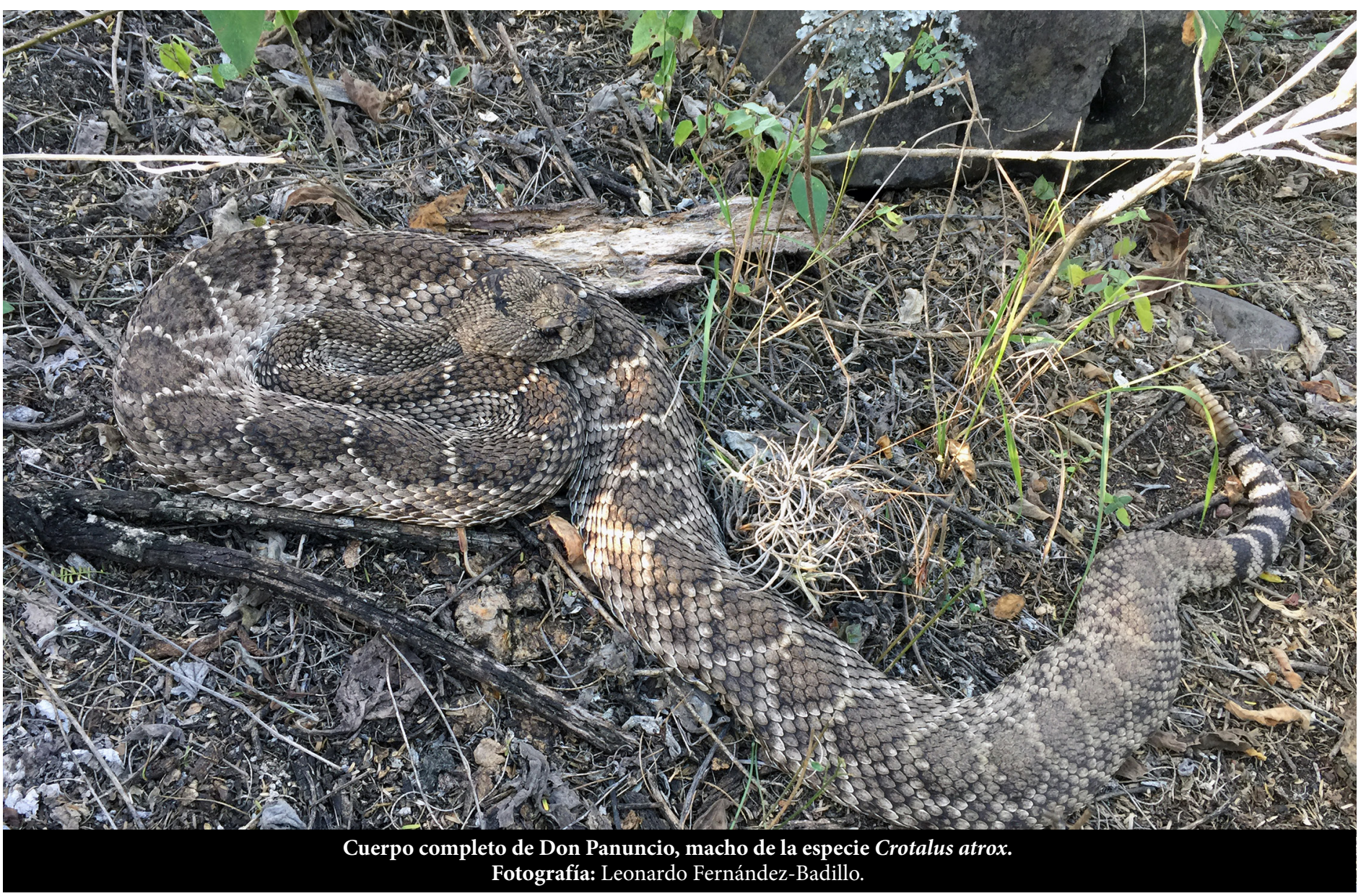

tuvo que descansar varios días bajo unas láminas que encontró. Una vez recuperado, comenzó la búsqueda de alimento y quedó maravillado, no podía creer la gran cantidad de ardillas de tierra que había en ese lugar, de esas rechonchas, gordotas, sabrosotas, que de tantas nueces que se comen ya ni pueden moverse bien y pareciera que, en vez de correr, ruedan y se van levantando la polvareda. El agua en abundancia y la sombra de los nogales terminaron de enamorarlo, dio un suspiró largo y exclamó: "con razón los humanos viven aquí, y yo que pensé que estaban bien caguengues".

Al principio Don Panuncio observaba a lo lejos a las personas y procuraba no molestarlas, escogía sitios poco concurridos para cazar y dormía donde no pudieran verlo, pero poco a poco fue tomando confianza y cada vez se aventuraba más, hasta llegó a pensar que quizás si alguna persona lo descubría, lo dejaría en paz, un error que casi le costaría la vida...

Tanto va el cántaro al agua que acaba por romperse; Don Panuncio tuvo un descuido y fue descubierto cerca de una parcela. Se hizo un alboroto, las mujeres del pueblo comenzaron a gritar y a correr, los hombres comenzaron a reunirse y a buscar palos y piedras para matarlo. El enojo y la desesperación se sentían en el aire, el terror de la gente se contagiaba y todos estaban muy asustados. Don Panuncio se enroscó y pensó, no quiero hacerlo, pero si alguien se acerca tendré que defenderme, y se colocó en posición defensiva, como un boxeador, con la guardia arriba y listo para la batalla. Sin embargo, nadie se acercaba, lo veían a lo lejos y solo decían, “ihijo de todos modos, está grandísimo!", "mira, tiene cabeza como de gato", "es un rollote". Su tamaño y esa cicatriz en la cabeza le daban un aspecto terrorífico, nadie quería acercarse. Don Panuncio no entendió por qué al final se alejaron, pero suspiró aliviado.

Después de varias horas, y pasado el susto, Don Panuncio decidió alejarse un poco y lentamente se refugió bajo una roca, no sabía si irse lo más lejos posible o si la gente ya había decidido dejarlo en paz. Temprano por la mañana sintió que alguien se acercaba y supo que habría problemas, los humanos habían vuelto. Confiaba plenamente en su escondite, sería difícil que lo vieran bajo la roca, pero sabía que, si lo descubrían, tendría que luchar por su vida. De pronto vio acercarse a un hombre que cargaba unas herramientas extrañas, era Guillermo Sánchez, le apodaban El Tigre. El hombre venía muy cauteloso, no traía piedras ni horquetas, y traía una especie de bastón que Don Panuncio nunca había visto. También traía otra cosa rara, como una cubeta para juntar la nuez, y unos como calcetines gigantes que le llegaban hasta las rodillas. Don Panuncio estaba bien camuflado, así que se mantuvo en silencio, si no sueno el cascabel, quizás no me encuentre, pensó. Pero El Tigre, aunque no siempre fue especialista en serpientes, se había convertido en el mejor de toda la barranca.

Con cautela, llegó directamente hasta donde estaba Don Panuncio, el resto de los pobladores permanecían en silencio y expectantes. Don Panuncio estaba preparado para la batalla 
y listo para defenderse, no había comido y tenía veneno de sobra. Pero pasó algo nunca antes visto, ni por Panuncio ni por los pobladores. El Tigre, protegido con sus polainas, que Don Panuncio confundió con calcetines, tomó su bastón herpetológico y con mucha gentileza levantó a la serpiente, procurando no hacerle daño y cuidando de que no se cayera, la colocó dentro de la cubeta. Don Panuncio no entendía lo que había pasado, pero estaba asustado, no sabía qué harían con él, y no había podido defenderse, algo en la mirada de aquel hombre le impidió morderlo y la forma en cómo lo levantó, le inspiró confianza.

Los pobladores dando brincos, echando gritos y con gran alboroto aplaudieron y felicitaron a El Tigre, esto era algo que no se veía todos los días. Muchos no comprendieron lo que pasó, así que le preguntaron por qué no había matado a la terrible serpiente. El Tigre les contó que él se dedicaba a rescatar serpientes, las sacaba de las casas o de los cultivos y las llevaba nuevamente al monte, les explicó también que, aunque son venenosas, si no se les molesta, ellas no nos harán daño, además les contó que son muy importantes, pues se comen las plagas de ardillas y otros animales que destruyen las cosechas y pidió a los pobladores que si encontraban otra lo llamaran y que no la mataran.

Al día siguiente El Tigre invitó a su hijo Memo Sánchez Cabrera, a su nuera Jas, a unos amigos de su hijo y a la bióloga Nallely Morales Capellán, y tomaron camino rumbo al monte, hacia la Peña del Cuervo. Don Panuncio seguía asustado, nunca había viajado en camioneta, el zangoloteo y la brincadera lo asustaban mucho. El Tigre seleccionó un sitio, sacó gentilmente a la serpiente del bote y la colocó en el suelo. Esta seguía sorprendida y no sabía cómo actuar, su naturaleza le obligaba a defenderse, pero algo le decía que no, que se contuviera. El Tigre y sus acompañantes retrocedieron unos pasos, se tomaron unos minutos para contemplar a Don Panuncio, sonrieron y se alejaron. Nunca más volverían a encontrarse.

Don Panuncio nunca regresó al pueblo, pero de vez en cuando se enteraba que a otra serpiente le había pasado lo mismo, y que ya había más personas que se dedicaban a rescatarlas, igual que El Tigre. Don Panuncio subió a la punta de la Peña del Cuervo, contempló de lejos el pueblo y pensó en Don Guillermo, El Tigre, un nombre que recordaría por el resto de su vida.

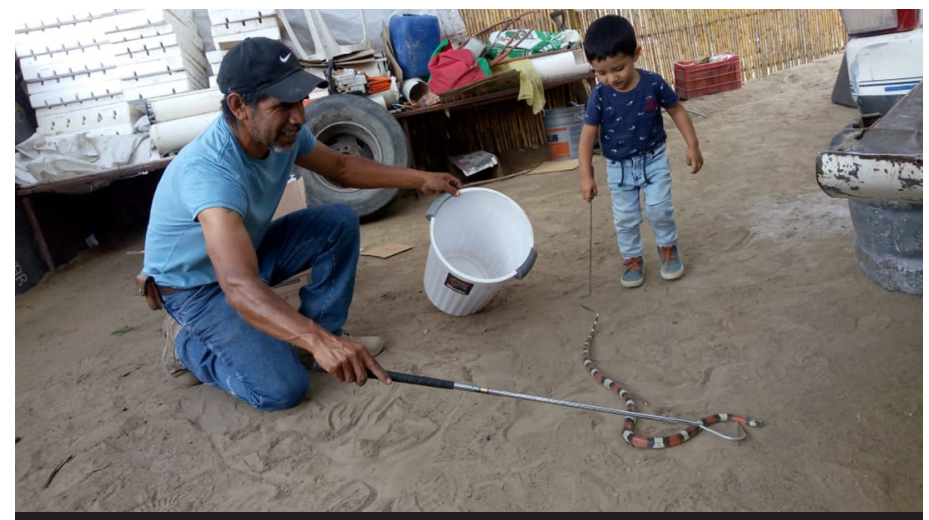

Guillermo Sánchez enseñándole manejo seguro de serpientes a su nieto Kenet. Fotografía: Ana Dary Sánchez-Cabrera.

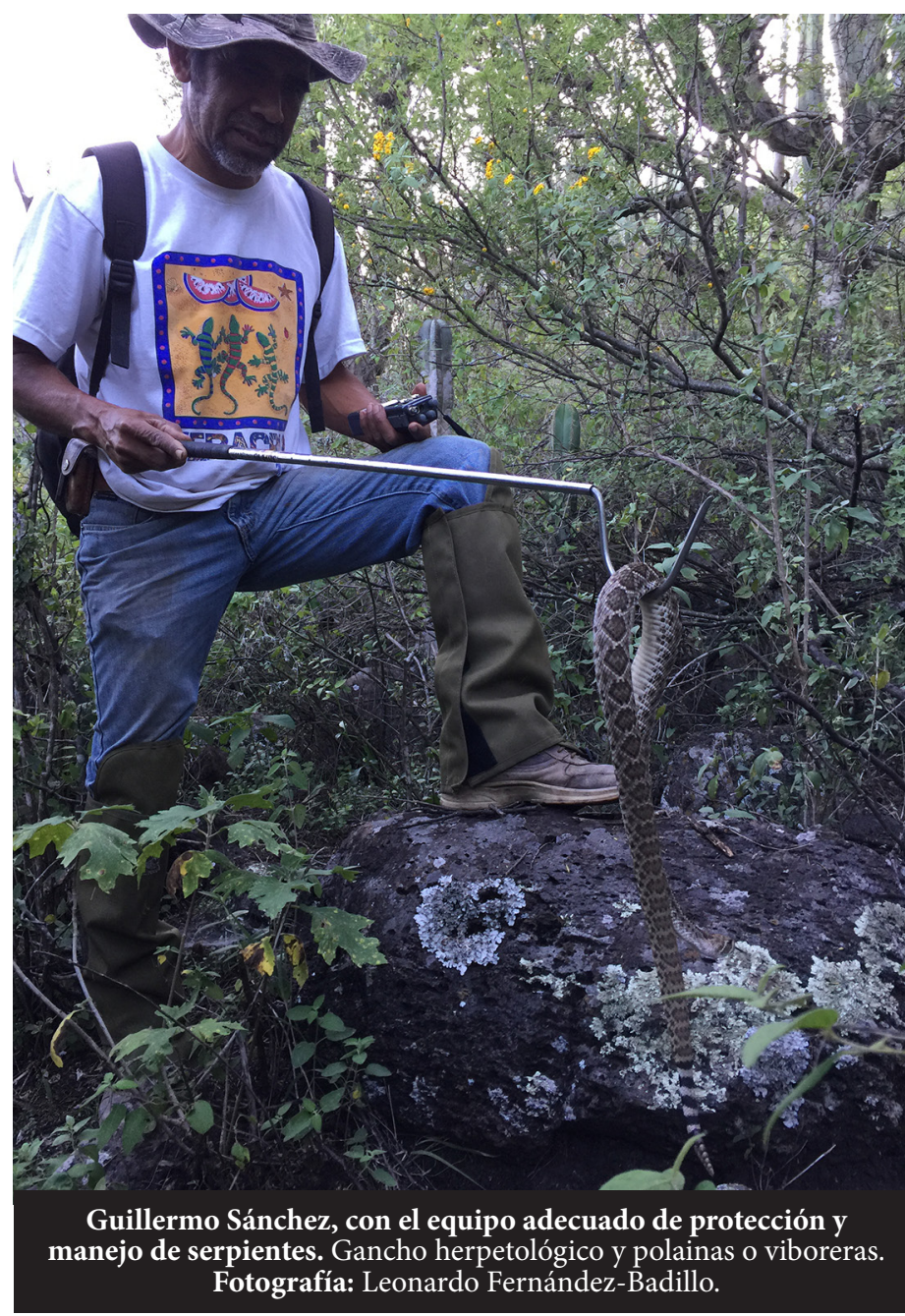

\section{Agradecimientos}

A Nalley Morales Capellán, por todo su apoyo y respaldo en todos los aspectos de mi vida, a mi comité de tesis, Iriana Zuria, Jesús Sigala Rodríguez, Gerardo Sánchez Rojas y Gamaliel Castañeda Gaytán, quienes me han apoyado y respaldado de forma excepcional. Al CONACyT por la beca no. 371195 otorgada para mi proyecto de doctorado. A Guillermo Sánchez, El Tigre por enseñarme a caminar y conocer el monte, por su insaciable curiosidad y su gran ejemplo, a toda la familia Sánchez por creer y confiar que podíamos conservar a las serpientes y hacerlo posible. A todos los pobladores que nos han ayudado a rescatar serpientes y que han sido parte de este proyecto, especialmente a Caín Montañez y su familia, a Don Pablo Mérida y a Don Buyo de Rancho Alegre. A todos los miembros de la brigada comunitaria de rescate de serpientes de la Barranca de Metztitlán por su gran trabajo y compromiso con la conservación. A Edgar Hugo Olvera Delgadillo, director de la Reserva de la Biosfera Barranca de Metztitlán, así como a Greisy Flores Sierra y Alberto Aspeitia personal de esta misma ANP, por su apoyo y gestión para la conformación de la brigada. A todos los voluntarios del herpetario que nos acompañaron a monitorear a las serpientes y a los estudiantes de distintas universidades que pudieron apreciar a estas formidables serpientes. A Iriana Zuria Jordan, Consuelo Cuevas Cardona y Amaya González Ruiz por los comentarios y sugerencias para enriquecer este cuento. 


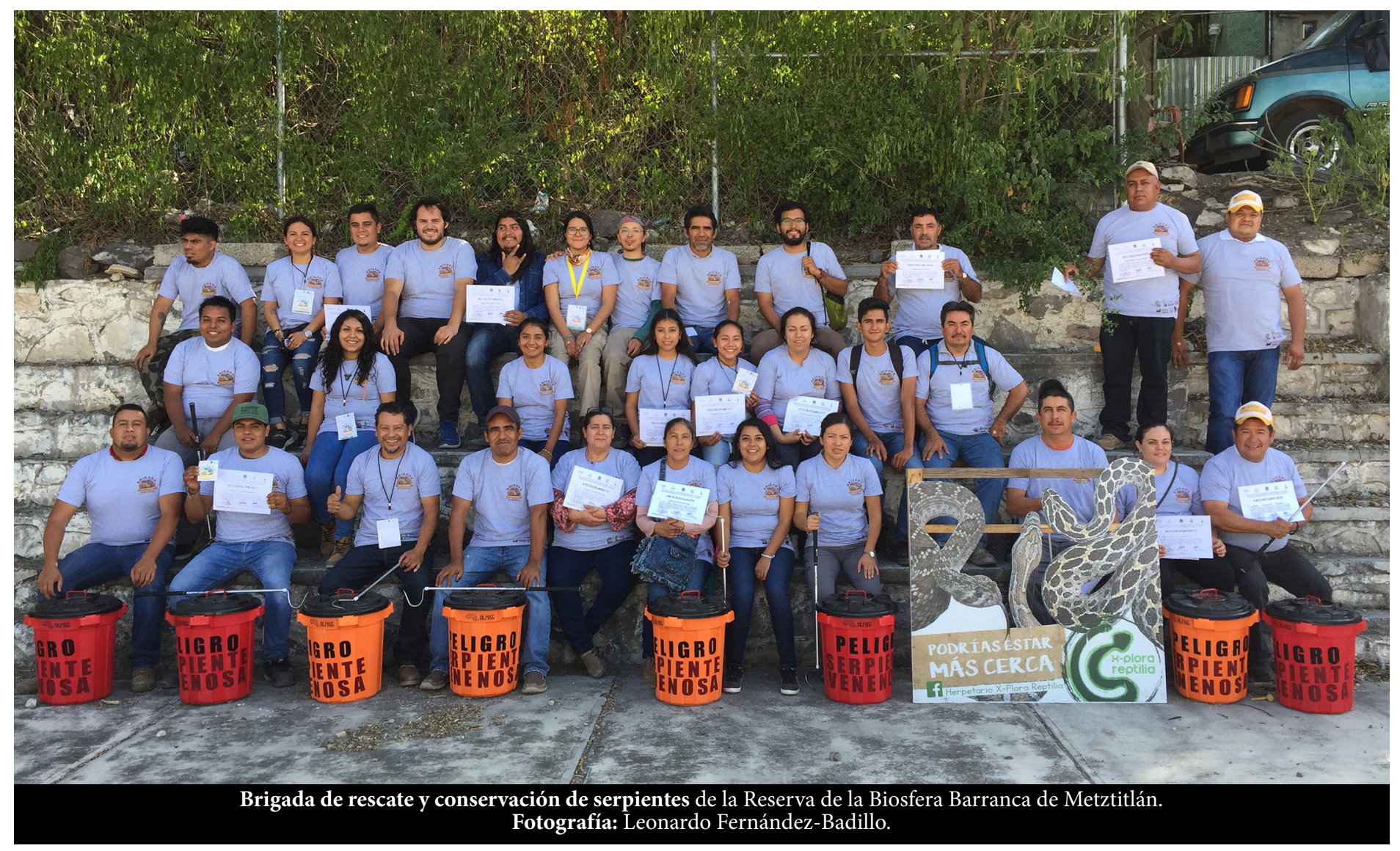

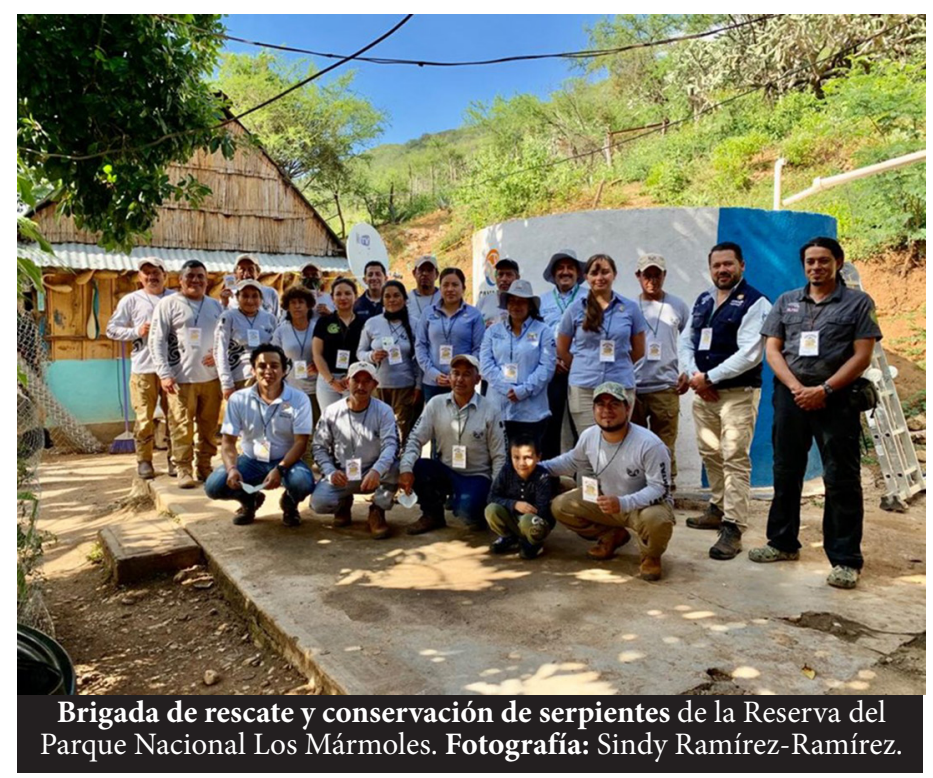

\section{Referencias}

Heimes, P. 2016. Herpetofauna Mexicana Vol. 1. Snakes of Mexico. Edition Chimaira, Framkfurt Am Main, Alemania.

Nowak, E. M., Hare, T y McNally, J. 2002. Management of "nuisance" vipers: effects of translocation on Western Diamond-backed Rattlesnakes (Crotalus atrox). En: Schuett, G. W., Höggren, M., Douglas, M. E. y Greene, H. W. (eds.). Biology of the Vipers. Eagle Mountain Publishing, L.C., Utah, USA, pp. 533-560.

Sullivan, B. K., Nowak, E. M y Kwiatowski, M. A. 2014. Problems with mitigation translocation of herpetofauna. Conservation Biology, 29: 12-18.

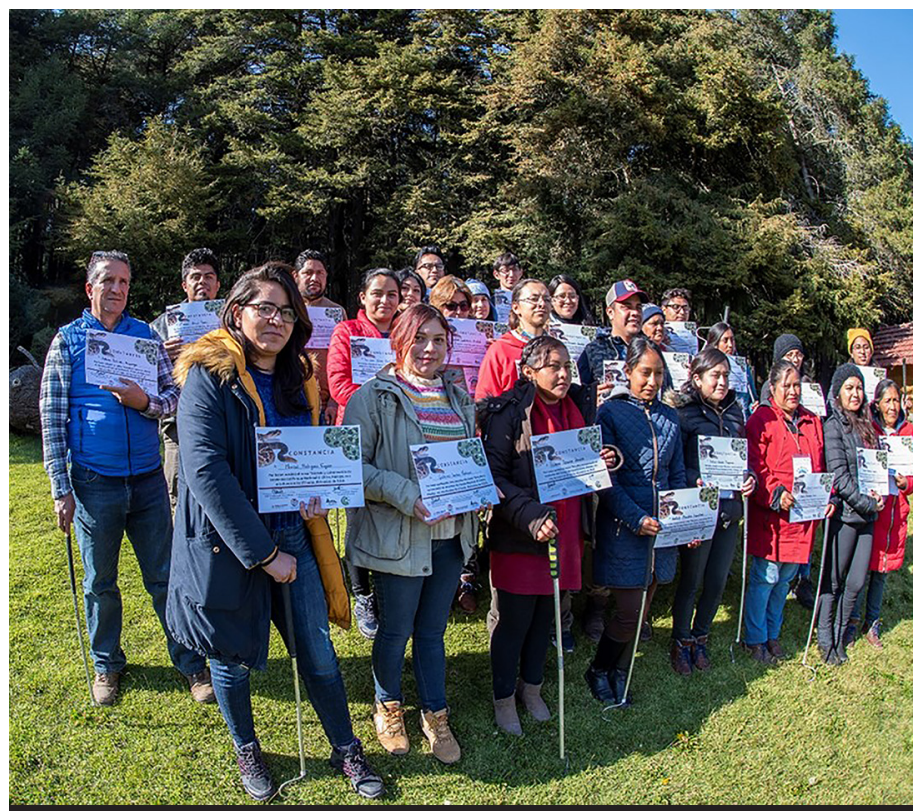

Brigada de rescate y conservación de serpientes del Parque Nacional El Chico. Fotografía: Leonardo Fernández-Badillo. 